\section{FLEXURAL LOAD AND DEFLECTION BEHAVIOR OF STRUCTURAL BAMBOO FILLED WITH CEMENT MORTAR}

Gathot Heri Sudibyoa,b, Nor Intang Setyo Hermantoa, HsuanTeh $\mathrm{Hu}^{c, d}$, Yanuar haryanto ${ }^{a, c^{*}}$, Laurencius Nugrohoc, Bagyo Mulyono $a, b$

aDepartment of Civil Engineering, Faculty of Engineering, Jenderal Soedirman University, JIn. Mayjen. Sungkono KM 5, Blater, Purbalingga, 53371, Indonesia

bDepartment of Civil Engineering, Faculty of Engineering, Diponegoro University, JIn. Prof. Soedarto, Tembalang, Semarang, 50275, Indonesia

'Department of Civil Engineering, College of Engineering, National Cheng Kung University, No. 1 University Road, Tainan, 701, Taiwan

'Department of Civil and Disaster Prevention Engineering, College of Engineering and Science, National United University, No. 2 Lien Da, Nan Shih Li, Miaoli, 36063, Taiwan
Article history

Received

21 November 2020

Received in revised form

31 March 2021

Accepted

20 April 2021

Published online

20 June 2021

*Corresponding author yanuar.haryanto@unsoed.ac.id

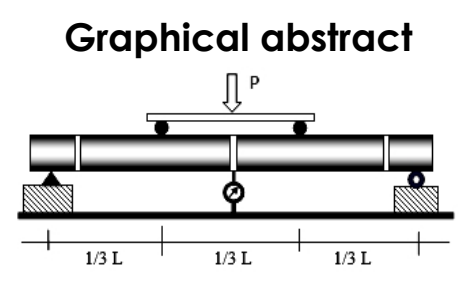

\begin{abstract}
Bamboo has been significantly and rapidly used to build temporal and permanent structures since time immemorial. However, this renewable natural material has a low bearing capacity, limiting its application to structures under light loads. Therefore, this research was carried out to determine an innovative scheme capable of enhancing bamboo's load-bearing by filling the cavity with cement mortar. Furthermore, a study was carried out to experiment flexural load carrying capacity and the deflection of mortar-filled structural bamboo by considering the diameter and node parameters. A total of 12 specimens were examined using a four-point bending protocol. The result showed the ultimate flexural load carrying capacity of mortar-filled bamboo specimens are higher than those of the conventional bamboo specimens. Specifically, mortar filled bamboo specimen with a diameter of $70 \mathrm{~mm}$ was significantly better, 41.10 and $47.06 \%$, as compared than the conventional bamboo in terms of its flexural load carrying capacity for specimen without and with nodes, respectively. Increases in flexural load carrying capacity were also observed for the mortar-filled bamboo specimens having 80 and $90 \mathrm{~mm}$ diameter and these observed increases were recorded as 104.55 and $112.00 \%$, and 48.72 and $60.74 \%$, respectively for specimen without and with nodes. Furthermore, the deflection of mortar-filled bamboo elements are substantially greater than those of conventional. Finally, the advantages of the bamboo diameter and bamboo nodes on the flexural load carrying capacity indicated that these essential findings need to be carefully considered in designing structural elements for both mortar-filled and conventional bamboos.
\end{abstract}

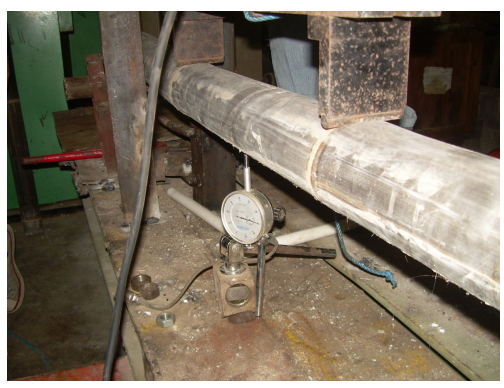

Keywords: Bamboo, mortar-filled bamboo, node, flexural load, deflection

(c) 2021 Penerbit UTM Press. All rights reserved 


\subsection{INTRODUCTION}

Bamboos are some of the fastest-growing plants worldwide and have been widely used to build permanent and temporary structures since time immemorial. This plant is one of the sustainable materials that serve as an environmentally friendly and competitive alternative to nonrenewable as well as polluting materials, namely concrete and steel with mechanical properties similar to timber [1, 2, 3, 4]. Over the past few years, numerous experimental and analytical studies have been conducted on structural bamboo's mechanical properties $[5,6,7]$. For instance, Gottron et al. [8] carried out a research to determine bamboo's creep behavior due to the specimen orientation. They found that bamboos loaded with outer culm-wall in tension (OT) indicated a larger modulus of rupture, as well as a lower residual strength and apparent modulus elasticity than those with outer culm-wall in compression (OC). A research carried out by Moran et al. [9] to determine the distribution of the circumferential elastic modulus through the wall and the associated failure strain and stress, mean effective moduli were found to be $1358.5 \mathrm{MPa}, 662 \mathrm{MPa}$, and $862 \mathrm{MPa}$ for bamboo species of Moso, Tre Gai, and Guadua, respectively.

Also, several studies have been conducted to investigate bamboo as reinforcement in structural concrete $[10,11,12,13,14,15]$. One of such study was carried out by Haryanto et al. [16], who examined the performance of precast segmental bamboo reinforced concrete beams after exposing them to flexural loads. A flexural failure mechanism was indicated by the pattern of crack observed in the control beam. On the contrary, a shear failure mechanism was indicated in the precast segmental bamboo reinforced concrete beams. In comparison with the precast segmental bamboo reinforced concrete beams containing four bolted connections, the same containing six bolted connections demonstrated better performance. Furthermore, an experiment conducted by Haryanto et al. [17] with bamboo used as the reinforcing material in the slab specimen for the utilization of footplate foundations showed that compared to steel reinforced concrete (SRC) slabs, strength of $82 \%$ can be acquired by the bamboo reinforced concrete (BRC) slabs. Furthermore, ductility and stiffness demonstrated by the two types of specimens investigated were almost equivalent, with percentages of 93 and $72 \%$, respectively.

In addition, varieties of investigation have been carried out in recent years to improve the reinforced concrete structures using bamboo as the strengthening material [18, 19, 20]. Haryanto et al. [21] stated that the flexural strength of reinforced concrete beam with near-surface mounted (NSM) bamboo reinforcement increased by $41.7 \%$, while the deflection ductility index reduced by $21.55 \%$ when compared to the control specimen. Furthermore, the research carried out on the finite element analysis (FEA) was similar to the experimental test. Hidayat et al. [22] also conducted a nonlinear finite element analysis to evaluate concrete beams flexurally strengthened using bamboo and concluded that the load-carrying capacity improved due to the placement of bamboo plates.

In accordance with the above studies, bamboo is defined as an attractive and widely used material that is an alternate to steel because of the high tensile strength, that range between $100 \mathrm{MPa}$ to $400 \mathrm{MPa}$ [23]. In addition, some bamboo, have similar tensile strength to mild steel strength. However, bamboos compressive strength in the cylindrical section is lower than the tensile, which ranges between 12-65 MPa [24, 25, 26]. According to Li et al. [23], bamboo's low comprehensive strength, tends to limits its applications only to light load structures, namely low-rise houses, short footbridges, scaffolds, and roof structures.

Numerous studies have been conducted on structural bamboo's mechanical properties, and bamboo as reinforcement and strengthening materials in concrete members. However, little or no research has been carried out to improve conventional structural bamboo's load-carrying capacity in flexure. Therefore, this research improved the flexural capacity of bamboo, using an effective and easy scheme. The flexural capacity of structural bamboo was enhanced by filling cement mortar in the material's cavity. Hence, this exploratory research is used to verify the feasibility of the proposed scheme as well as the experimental behavior of structural bamboo, which is filled with cement mortar that is under flexural load.

\subsection{EXPERIMENTAL PROGRAM}

\subsection{Test Specimen}

A total of 12 specimens, comprising of 3 cement mortar-filled bamboo elements with nodes, 3 cement mortar-filled bamboo elements without nodes, and 6 conventional bamboo with and without nodes, with a nominal diameter of 70,80 , and $90 \mathrm{~mm}$, were tested under four-point bending loading. The specimens' details are shown in Figure 1, while the properties are listed shown in Table 1.

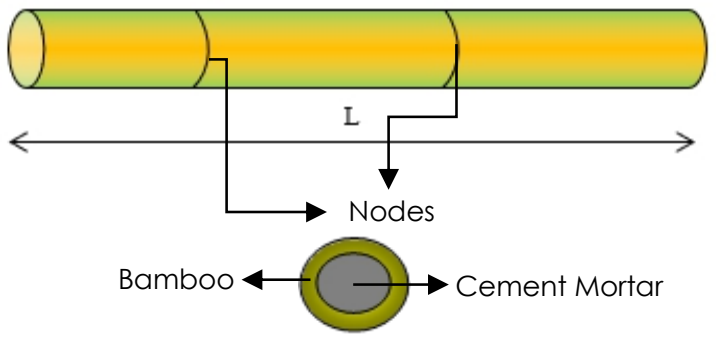

Figure 1 Details of test specimens 
Table 1 Properties of specimens

\begin{tabular}{ccccc}
\hline Specimen & $\mathbf{L}(\mathbf{m m})$ & $\mathbf{D}(\mathbf{m m})$ & Material infilled & Node \\
\hline SB-01 & 1350 & 70 & - & without \\
SB-02 & 1350 & 70 & - & with \\
SB-03 & 1350 & 70 & Cement mortar & without \\
SB-04 & 1350 & 70 & Cement mortar & with \\
SB-05 & 1350 & 80 & - & without \\
SB-06 & 1350 & 80 & - & with \\
SB-07 & 1350 & 80 & Cement mortar & without \\
SB-08 & 1350 & 80 & Cement mortar & with \\
SB-09 & 1350 & 90 & - & without \\
SB-10 & 1350 & 90 & - & with \\
SB-11 & 1350 & 90 & Cement mortar & without \\
SB-12 & 1350 & 90 & Cement mortar & with \\
\hline
\end{tabular}

The structural material used in this study is Java Black bamboo, also known as Gigantochloa atroviolacea, due to its suitability and use in furniture and interior artifacts [27]. In addition, cement mortar was selected as the infilled material due to its ability to be used as construction materials that is compressible and compatible with bamboo [23]. The bamboo diameter and nodes are key components that influences the flexural load of structural bamboo filled with cement. Therefore, this study also examined the attributes of the bamboo's nodes and diameter.

Table 1 shows that the total span of each test specimen (L) was $1350 \mathrm{~mm}$, which are classified into three groups in accordance with the external diameters (D). These groups are as follows: specimens SB-01-SB-04, SB-05-SB-08, and SB-9-SB12, with external diameters of 70,80 , and $90 \mathrm{~mm}$. Furthermore, the bamboos used for the test were carefully picked from the 3 year old Java Black bamboo stems, which are 4 $\mathrm{m}$ in length and about $50-100 \mathrm{~mm}$ in wall thickness, in order to ensure the specimens have the right dimensions. All the bamboo culms utilized in this research were dried for 3 months to obtain a moisture content that is below $10 \%$.

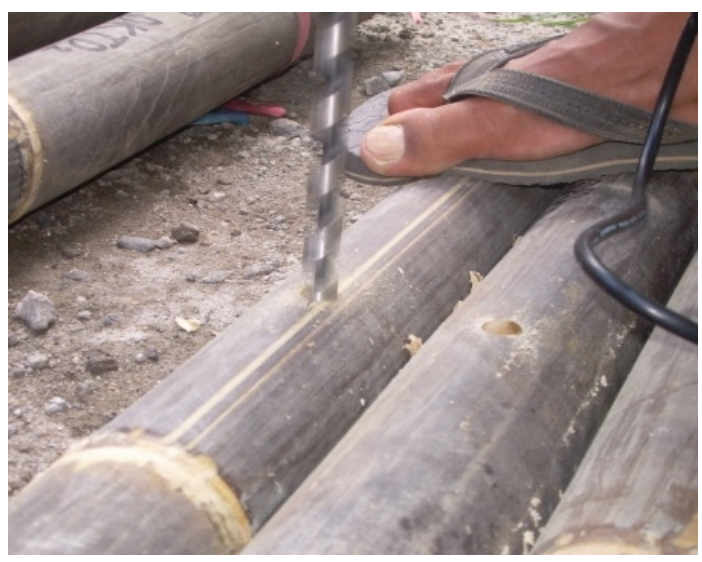

(a) Drilling a hole

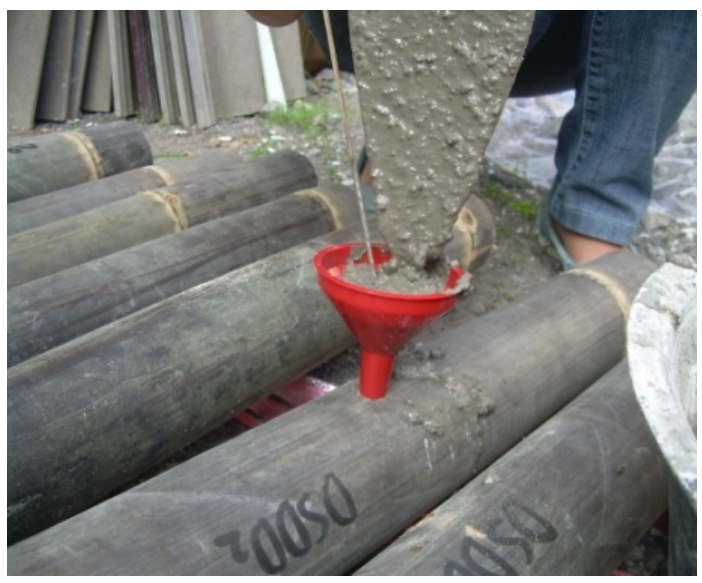

(b) Pouring cement mortar

Figure 2 Casting process

Specimens SB-02, SB-04, SB-06, SB-08, SB-10, and SB-12 were arranged with five bamboo nodes while others were without the nodes. For those with nodes, the traversal diaphragm was drilled to make a hole before casting cement mortar into the cavity, as shown in Figure 2. Furthermore, the cement mortar specimens were cured by covering their surfaces with wet gunny bags and tested after 28 days.

\subsection{Material Properties}

According to Ghavami [10], García et al. [2], Sharma et al. [5], Lee et al. [6], and Moran et al. [9], bamboo is a material with high and low strength in the parallel and perpendicular direction to the fibers, respectively. Furthermore, bamboo's compressive strength in the cylindrical section is lower than the tensile strength [24, $25,26]$. Therefore, the preliminary tests of bamboo material in this research were conducted to determine the physical proprieties such as the moisture content (MC) and specific density (SD), and the mechanical properties such as compressive strength, tensile strength, shear strength, and flexural strength. Since there is a lack of standardization of culm bamboo material as a construction material due to large number of bamboo species and geometry, this study refers to ISO 3129-1975 [28], the wood international standard for sampling method requirement of physical and mechanical testing by used small specimens. The specimens used are depicted in Figure 3.

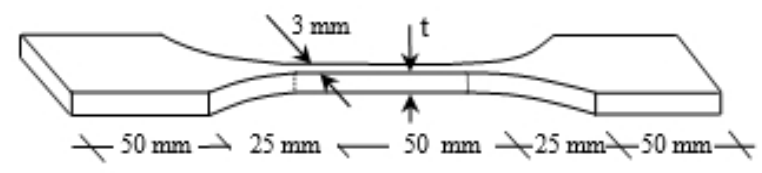

(a) Tensile strength specimen 


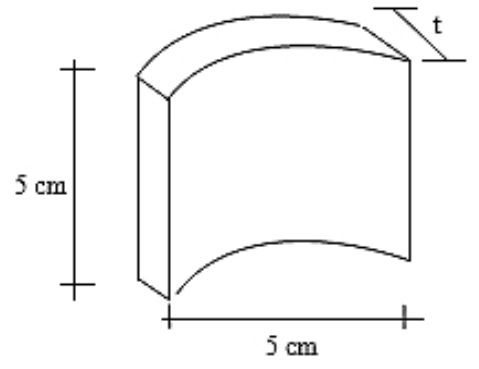

(b) Moisture content and specific density specimen

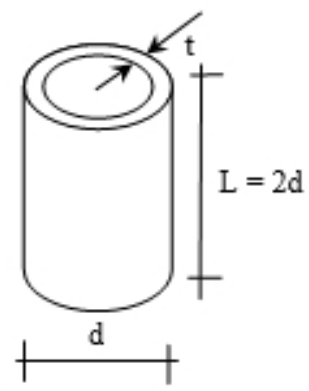

(c) Compressive strength specimen

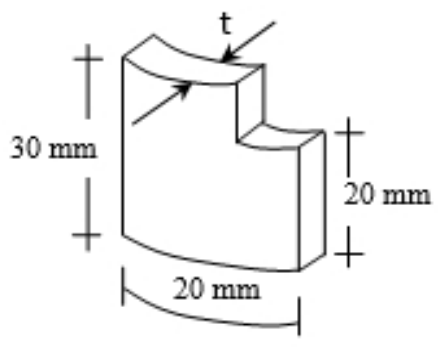

(d) Shear strength specimen

Figure 3 Detail specimens for material properties of bamboo

By measuring the moisture content of chosen bamboo culms for the development of mortar-filled bamboo specimens, a preliminary estimation of the required time to achieve a certain $M C$ percentage suitable for processing of the raw bamboo and fabrication of the specimens became possible. The average MC of Java Black bamboo in this study was 7.28\%. According to Javadina et al. [29], the average MC used for processing the bamboo needs to be less than $10 \%$ in order to reduce excessive delamination as well as long-term environmental negative impacts due to the degradation of the final composite product.

The average SD for Java Black bamboo used for this study was 0.572. Generally, bamboo culms have higher fiber density at top parts where the fibers are closely packed as has been shown by other studies on microstructure of bamboo culm of different species [30, 31]. As a result, the SD will be lower in the bottom parts where the culm diameter and wall thickness are much greater as compared to the middle and top parts. In addition, the tensile strength and modulus of elasticity results in the tension tests of the Java Black bamboo samples along the fiber direction were 114.27 and 3682.20 MPa, respectively. According to Javadian et al. [29], bamboo's high tensile capacity is significantly influenced by the cellulose fibers.

The compression and shear tests results of the Java Black bamboo in this study were 44.65 and 8.50 $\mathrm{MPa}$, respectively. Meanwhile, the flexural and modulus of elasticity results in flexure tests of the Java Black bamboo were 93.29 and $4733.82 \mathrm{MPa}$, respectively. Cellulose fibers largely contribute to the increase in mechanical properties of bamboo, which is greater than the wall sections' outer layer and above the culms. Javadian et al. [29] stated that the Modulus of Rupture (MOR) or flexural strength increases with a rise in fiber and decreases the lignin content in the surroundings. Javadian et al. [29] further stated that the effect of the culm on the modulus is similar to MOR, which tends to increase the culm diameter with a decrease in average modulus. This observation is due to the culm sequential microstructure, which increases at the middle and bottom sections of the bamboo. Furthermore, the fiber density tends to decrease due to the high lignin content. Finally, Table 2 summarizes the physical and mechanical properties of Java Black bamboo used in this study in accordance with ASTM D143-94 [32].

Table 2 Physical and mechanical properties

\begin{tabular}{lc}
\hline \multicolumn{1}{c}{ Bamboo Properties } & $\begin{array}{c}\text { Average } \\
\text { Value }\end{array}$ \\
\hline Physical Properties & \\
Moisture content $(\%)$ & 7.28 \\
Specific density $\left(\mathrm{gr} / \mathrm{cm}^{3}\right)$ & 0.572 \\
Mechanical Properties & \\
Compressive strength parallel to grain, $f_{c, 0}(\mathrm{MPa})$ & 44.65 \\
Tensile strength parallel to grain, $\mathrm{f}_{t, 0}(\mathrm{MPa})$ & 114.27 \\
Shear stress parallel to grain, $\mathrm{f}_{\mathrm{s}, 0}(\mathrm{MPa})$ & 8.50 \\
Flexural strength (MPa) & 93.29 \\
Modulus of elasticity in tensile, $E_{T}(\mathrm{MPa})$ & 3682.20 \\
Modulus of elasticity in flexure, $E_{F}(\mathrm{MPa})$ & 4733.82 \\
\hline
\end{tabular}

\subsection{Instrumentation and Testing}

Figure 4 shows a dial gauge's installation process placed in the mid-span and bottom of each mortarfilled bamboo specimen in order to monitor the flexural deformation. Furthermore, the specimens were examined under a 10,000 kN Universal Loading Machine and displacement control at a constant rate of $0.1 \mathrm{~mm} / \mathrm{min}$ to provide the deflection behavior. The tested data were also gathered with a data logger.

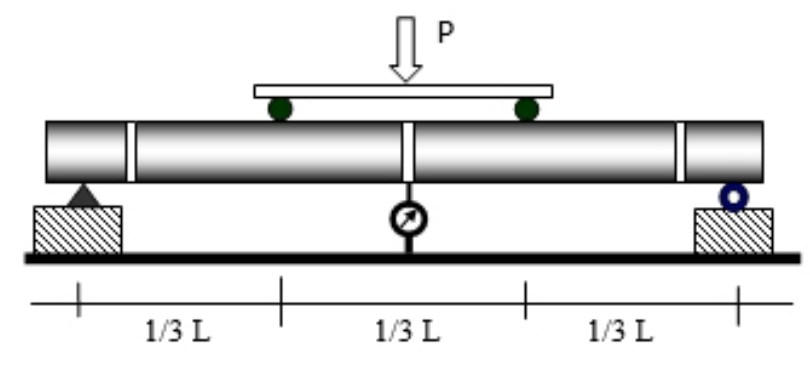

Figure 4 Test setup and instrumentation 


\subsection{RESULTS AND DISCUSSION}

This section thoroughly presents the observed and measured results for the flexural load carrying capacity and deflection behavior of the specimens due to the effect of infilled cement mortar, bamboo diameter, and bamboo nodes as listed in Table 3.

Table 3 Result of the maximum of flexural load and deflection

\begin{tabular}{ccc}
\hline Specimen & Load $(\mathbf{k N})$ & Deflection $(\mathbf{m m})$ \\
\hline SB-01 & 3.50 & 17.45 \\
SB-02 & 4.25 & 16.80 \\
SB-03 & 5.00 & 27.17 \\
SB-04 & 6.25 & 15.48 \\
SB-05 & 5.50 & 18.20 \\
SB-06 & 6.25 & 15.80 \\
SB-07 & 11.25 & 37.16 \\
SB-08 & 13.25 & 33.32 \\
SB-09 & 9.75 & 20.45 \\
SB-10 & 10.75 & 18.94 \\
SB-1 & 14.50 & 35.12 \\
SB-12 & 17.25 & 24.10 \\
\hline
\end{tabular}

\subsection{Effect of the Infilled Mortar}

Figure 5 shows the mortar's infilled effect on the flexural behavior of the specimens with the flexural load carrying capacity of mortar-filled bamboo was greater than the conventional. Mortar-infilled bamboo element with a $70 \mathrm{~mm}$ diameter was significantly better at 42.86 and $47.06 \%$, compared to the conventional in terms of flexural load carrying capacity for specimen without and with nodes, respectively. Furthermore, an increase in flexural load carrying capacity were observed for the mortar-filled bamboo element with diameters of 80 and $90 \mathrm{~mm}$, and these observed increases were verified as $104.55 / 112.00 \%$, and $48.72 / 60.74 \%$, for specimen without and with nodes, as shown in Figure 5. This proves a direct relationship between the mortar-filled and the percentage increase in flexural load carrying capacity with a significant impact on both bamboo without and with nodes. The mortar-filled enhances the flexural capacity due to the increase in the specimens' moment of inertia.

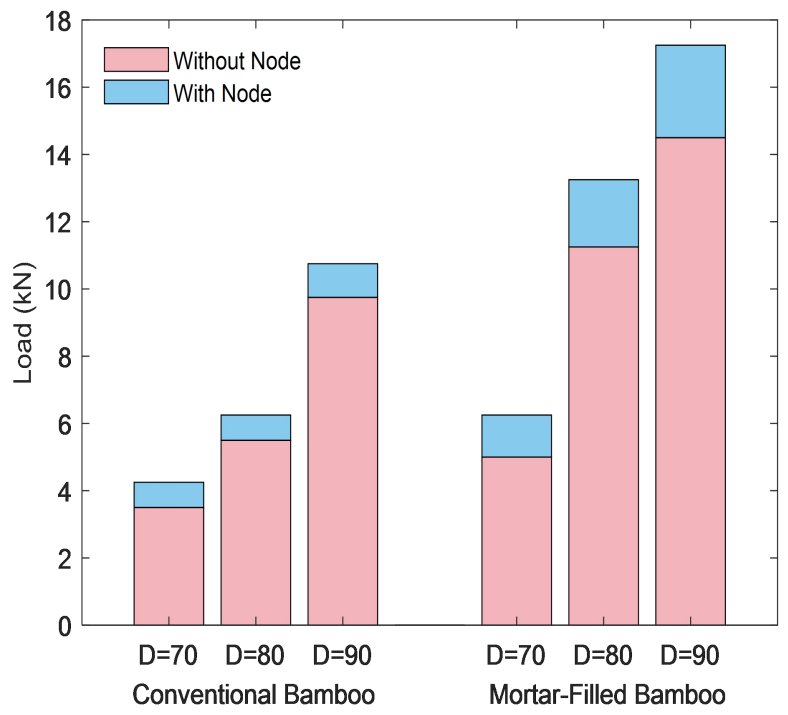

Figure 5 Effect of the infilled mortar on the specimens' flexural load carrying capacity

\subsection{Effect of Bamboo Diameter}

This study also explored the effect associated with bamboo diameter on the performance of mortar-filled bamboo elements, as also shown in Figure 5. The figure indicated that the specimen with a $70 \mathrm{~mm}$ diameter has the lowest flexural load carrying capacity compared to those with a diameter of 80 and $90 \mathrm{~mm}$. 
Figure 5 also confirmed that the increase in the conventional bamboo's flexural load carrying capacity with a diameter of 80 and $90 \mathrm{~mm}$ were 57.14 and $178.57 \%$, respectively, in comparison with a diameter of $70 \mathrm{~mm}$. Furthermore, for the specimen with nodes, the increase in the conventional bamboo's flexural load carrying capacity with a diameter of 80 and $90 \mathrm{~mm}$ was 47.06 and $152.94 \%$ compared to a diameter of $70 \mathrm{~mm}$, respectively. It can be observed from Figure 5 that the increase in the mortar-filled bamboo's flexural load carrying capacity with a diameter of 80 and $90 \mathrm{~mm}$ was 125 and $190 \%$ for the specimen without nodes, over the specimen with a diameter of $70 \mathrm{~mm}$. In addition, for the specimen with nodes, the increase in the flexural load carrying capacity of the mortar-filled bamboo with a diameter of 80 and $90 \mathrm{~mm}$ was 112 and $176 \%$ over a diameter of $70 \mathrm{~mm}$. These essential findings need to be taken into account to design the structural elements for conventional bamboo and those filled with cement mortar.

\subsection{Effect of Bamboo Nodes}

As also shown in Figure 5, bamboo nodes' beneficial effect on the flexural load carrying capacity of the specimens can be found in both conventional and mortar-filled bamboo. The flexural load carrying capacity of specimens with nodes were higher than those without nodes. In particular, conventional bamboo element with nodes was meaningfully higher, 21.43 , 13.64, and $10.26 \%$, as compared than the conventional bamboo in regards of its flexural load carrying capacity for specimen having diameter of 70 , 80 , and $90 \mathrm{~mm}$, respectively. Increases in flexural load carrying capacity were indicated for the mortar-infilled bamboo with nodes, and these observed increases were noted as $25.00,17.78$, and $18.97 \%$, respectively for specimen having diameter of 70,80 , and $90 \mathrm{~mm}$. These results illustrate that the nodes' integrity is imperative for the flexural load carrying capacity both of conventional and mortar-filled bamboo elements.

\subsection{Deflection Behavior}

Figure 6 shows the deflection value for all specimen types, including conventional and mortar-filled bamboo elements. Furthermore, the figure indicates that the deflection values of mortar-filled bamboo specimens are higher than those of the conventional bamboo specimens. The mortar-filled bamboo element with a $70 \mathrm{~mm}$ diameter was significantly greater, by 55.70 and $44.51 \%$, compared to the conventional bamboo in terms of the deflection for specimen without and with nodes, respectively. An increase in the deflection value was also observed for the mortar-filled bamboo element having 80 and 90 $\mathrm{mm}$ diameter, which increased by 104.18 and $110.86 \%$ and 71.74 and $27.24 \%$, respectively for specimen without and with nodes. Therefore, this indicates a direct relationship between the mortar-filled with a percentage increase in deflection value for both bamboos without and with nodes. Mortar-filled causing enhancement in deflection value, attributed to the fact that the mortar-filled results in a change of the physical form of the specimens that has considerable influence on the total deflection to be expected [33]. Finally, the increase of bamboo diameter that provides additional stiffening enhances the resistance of the specimens to loading, leading to greater deflection in the specimens. Unfortunately, in some cases, the benefit of this stiffening is unpredictable [33].

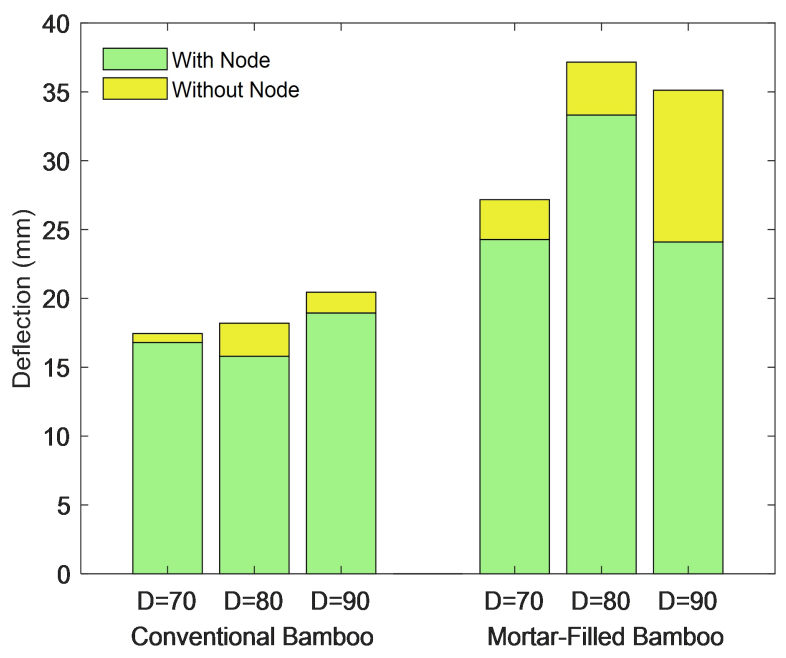

Figure 6 Deflection value 


\subsection{General Failure Modes}

Failure modes in flexural elements are classified into two major types: flexural failure and shear failure. The former occurs when the imposed load exceeds the flexural capacity of the materials of the beam, while the latter occurs due to deficiency in shear resistance between different materials of the beam. In this study, the general failure trend in specimens with nodes present consistently originated from the node scar located at the tension side where the diaphragms were once present. Upon further loading, it initiated a lateral shearing failure while reaching its ultimate flrxufral load carrying capacity. Comparatively, for the specimens without nodes, the failure mode also showed a transverse failure no the tension side with some lateral shear. Furthermore, after removing the covering bamboo, it was observed that infilled mortar were crushed, showing that the strength of infilled material was fully utilized. The general failure modes of the specimens are illustrated in Figure 7.

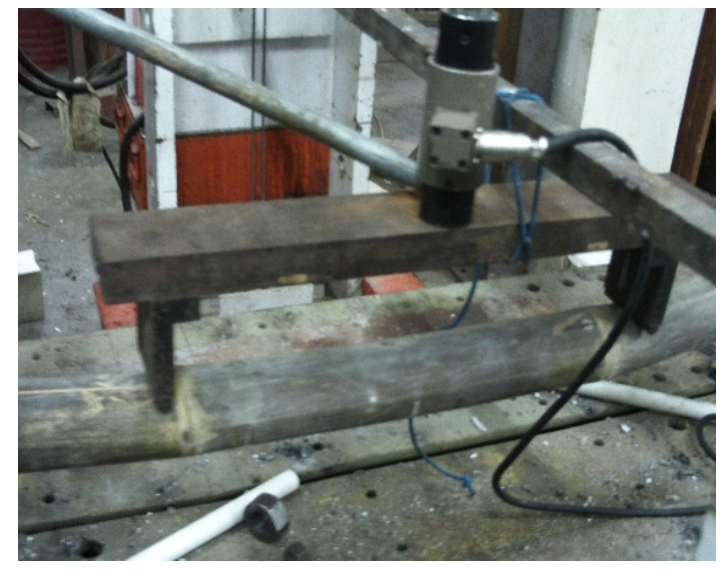

(a) Failure due to flexural load

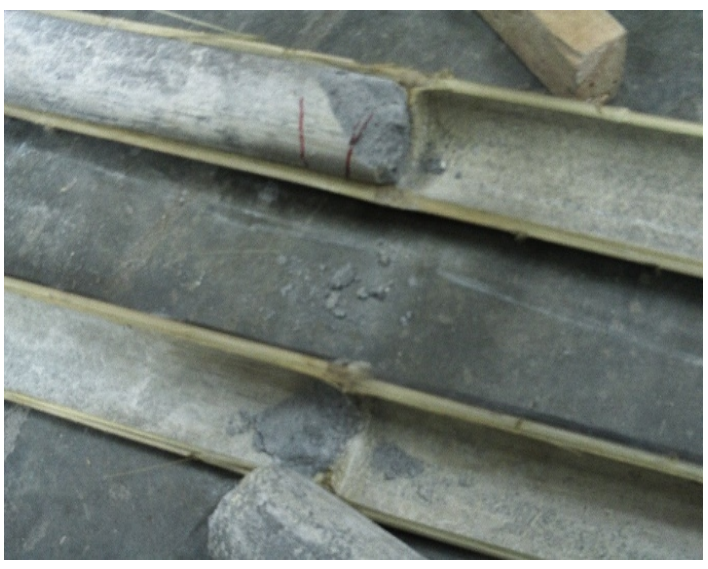

(b) Inilled mortar

Figure 7 General failure modes of the specimens

\subsection{CONCLUSIONS}

This research examined the flexural performance of structural bamboo filled with cement mortar. The study was carried out by testing a total of 12 specimens under four-point bending protocols to ascertain the aftermath of the infilled materials, bamboo diameter, as well as the nodes on the flexural load carrying capacity and deflection behavior of the specimens. Therefore, the following conclusions were made:

Mortar-infilled bamboo element with a diameter of $70 \mathrm{~mm}$ was significantly better, 41.10 and $47.06 \%$, as compared to the conventional bamboo in terms of its flexural load carrying capacity for specimen without and with nodes, respectively. Increases in flexural load carrying capacity were also observed for mortarinfilled bamboo element having 80 and $90 \mathrm{~mm}$ diameter by 104.55 and $112.00 \%$, and 48.72 and $60.74 \%$, respectively for specimen without and with nodes. This finding verified the feasibility of the proposed stiffening scheme for conventional structural bamboo. In addition, it is efficient to increase the flexural load carrying capacity by filling cement mortar. The experimental flexural load carrying capacities of conventional and mortar-filled bamboo elements tend to rise with an increase in diameter. Therefore, the bamboo diameter is significant and cannot be ignored. The beneficial effect of the nodes on the flexural load carrying capacity is present in both conventional bamboo and mortar-filled bamboo elements, thereby indicating that the bamboo nodes' integrity is essential for their load carrying capacity. The distance between nodes need to be further considered in the future work.

The deflection of mortar-filled bamboo elements is significantly greater than those of conventional bamboo. This is attributed to the fact that the mortarinfilled bamboos change the physical form of the specimens that influence the total deflection to be expected. Furthermore, the increase of bamboo diameter that provides additional stiffening enhances the resistance of the specimens to loading, leading to greater deflection in the specimens. The loaddisplacement responses need to be further analyzed in the future study. After removing the covering bamboo, it was observed that infilled mortar were crushed, showing that the strength of infilled material was fully utilized.

\section{Acknowledgement}

The authors are grateful to the Jenderal Soedirman University, Indonesia, for funding this research. The authors are also appreciate for the assistance provided by Fidia Rahmawati in performing different tests. 


\section{References}

[1] Yu, D., Tan, H., and Ruan, Y. 2011. A Future BambooStructure Residential Building Prototype in China: Life Cycle Assessment of Energy Use and Carbon Emission. Energy and Buildings. 43: 2638-2646.

DOI: https://doi.org/10.1016/j.enbuild.2011.06.013.

[2] García, J. J., Rangel, C., and Ghavami, K. 2012. Experiments with Rings to Determine the Anisotropic Elastic Constants of Bamboo. Construction and Building Materials. 31: 52-57. DOI: https://doi.org/10.1016/j.conbuildmat.2011.12.089.

[3] Sharma, B., Gatóo, A., and Ramage, M. H. 2015. Effect of Processing Methods on the Mechanical Properties of Engineered Bamboo. Construction and Building Materials. 83: 95-101.

DOI: https://doi.org/10.1016/j.conbuildmat.2015.02.048.

[4] Salcido, J. C., Raheem, A. A., and Ravi, S. 2016. Comparison of Embodied Energy and Environmental Impact of Alternative Materials Used in Reticulated Dome Construction. Building and Environment. 96: 22-34. DOI: https://doi.org/10.1016/j.buildenv.2015.11.010.

[5] Sharma, B., Harries, K. A., and Ghavami, K. 2013. Methods of Determining Transverse Mechanical Properties of Full-Culm Bamboo. Construction and Building Materials. 38: 627-637. DOI: https://doi.org/10.1016/j.conbuildmat.2012.07.116.

[6] Lee, P.-H., Odlin, M., and Yin, H. 2014. Development of A Hollow Cylinder Test for The Elastic Modulus Distribution and the Ultimate Strength of Bamboo. Construction and Building Materials. 51: 235-243.

DOI: https://doi.org/10.1016/j.conbuildmat.2013.10.051.

[7] Xu, Q., Harries, K., Li, X., Liu, Q., and Gottron, J. 2014. Mechanical Properties of Structural Bamboo Following Immersion in Water. Engineering Structures. 81: 230-239. DOI: https://doi.org/10.1016/j.engstruct.2014.09.044.

[8] Gottron, J., Harries, K. A., and XU, Q. 2014.Creep Behaviour of Bamboo. Construction and Building Materials. 66: 79-88. DOI: https://doi.org/10.1016/j.conbuildmat.2014.05.024.

[9] Moran, R., Webb, K., Harries, K., and García, J. J. 2017. Edge Bearing Tests to Assess the Influence of Radial Gradation on the Transverse Behavior of Bamboo. Construction and Building Materials. 131: 574-584. DOI: https://doi.org/10.1016/j.conbuildmat.2016.11.106.

[10] Ghavami, K. 2005. Bamboo as Reinforcement in Structural Concrete Elements. Cement and Concrete Composites. 27(6): 637-349.

DOI: https://doi.org/10.1016/j.cemconcomp.2004.06.002.

[11] Lima Jr, H. C., Willrich, F. L., Barbosa, N. P., Rosa, M. A., and Cunha, B. S. 2008. Durability Analysis of Bamboo as Concrete Reinforcement. Materials and Structures. 41: 981989.

DOI: https://doi.org/10.1617/s11527-007-9299-9.

[12] Moroz, J. G., Lissel, S. L., and Hagel, M. D. 2014. Performance of Bamboo Reinforced Concrete Masonry Shear Walls. Construction and Building Materials. 61: 125-137. DOl: https://doi.org/10.1016/j.conbuildmat.2014.02.006.

[13] Agarwal, A., Nanda, B., and Maity, D. 2014. Experimental Investigation on Chemically Treated Bamboo Reinforced Concrete Beams and Columns. Construction and Building Materials. 71: 610-617.

DOI: https://doi.org/10.1016/j.conbuildmat.2014.09.011.

[14] Archila, H., Harries, K. A., Kaminski, S., Trujillo, D., and Escamilla, E. Z. 2018. Bamboo Reinforced Concrete: A Critical Review. Materials and Structures. 51 (102): 1-18. DOI: https://doi.org/10.1617/s11527-018-1228-6.

[15] Muhtar. 2020. Precast Bridges of Bamboo Reinforced Concrete in Disadvantaged Village Areas in Indonesia. Applied Sciences. 10(20): 7158.

DOI: https://doi.org/10.3390/app10207158.

[16] Haryanto Y., Hu, H-T., Han, A. L., Wariyatno N. G., Sudibyo, G. H., Hidayat, B. A., and Naqiyah, K. 2019. Precast Segmental Bamboo Reinforced Concrete Beams with Bolted Connections Subjected to Flexural Loads: An Experimental
Investigation. IOP Conference Series: Material Science and Engineering. 615: 012070.

DOl: https://doi.org/10.1088/1757-899X/615/1/012070.

[17] Haryanto, Y. Wariyatno, N. G., Hu, H.-T., Han, A. L., and Hidayat, B. A. 2021. Investigation on Structural Behavior of Bamboo Reinforced Concrete Slabs Under Concentrated Load. Sains Malaysiana. 50(1): 227-238. http://dx.doi.org/10.17576/jsm-2021-5001-22.

[18] Sen, T., and Reddy, H. N. J. 2011. A Numerical Study of Strengthening of RCC Beam Using Natural Bamboo Fibre. International Journal of Computer Theory and Engineering. 3(5): 707-713.

DOI: https://doi.org/10.7763/IJCTE.2011.V3.396

[19] Nahar, T. T., and Rahman, M. M. 2015. Strengthening of RCC Beams Using Bamboo Sticks. International Journal of Advanced Science and Technology. 79: 15-24.

DOI: http://dx.doi.org/10.14257/ijast.2015.79.02.

[20] Chin, S. C., Moh, J. N. S., Doh, S. I., Yahaya, F. M., and Gimbun J. 2019. Strengthening of Reinforced Concrete Beams Using Bamboo Fiber/Epoxy Composite Plates in Flexure. Key Engineering Materials. 821: 465-471. DOI: https://doi.org/10.4028/www.scientific.net/KEM.821.465

[21] Haryanto, Y., Gan, B. S., Widyaningrum, A., and Maryoto, A. 2017. Near Surface Mounted Bamboo Reinforcement for Flexural Strengthening of Reinforced Concrete Beams. Jurnal Teknologi (Sciences \& Engineering). 79(6): 233-240. DOI: https://doi.org/10.11113/jt.v79.10767.

[22] Hidayat, B. A., Hu, H.-T., Han, A. L.., Haryanto, Y., Widianingrum, A., and Pamudij, G. 2019. Nonlinear Finite Element Analysis of Traditional Flexural Strengthening Using Betung Bamboo (Dendrocalamus asper) on Concrete Beams. IOP Conference Series: Material Science and Engineering. 615: 012073. DOI: https://doi.org/10.1088/1757-899X/615/1/012073.

[23] Li, W.-T., Long, Y.-L., Huang, J., and Lin, Y. 2017. Axial Load Behavior of Structural Bamboo Filled with Concrete and Cement Mortar. Construction and Building Materials. 148: 273-287.

DOI: https://doi.org/10.1016/j.conbuildmat.2017.05.061.

[24] Dixon, P. G., Ahvenainen, P., Aijazi, A. N., Chen, S. H., Lin, S., Augusciak, P. K., Borrega, M., Svedström, K., and Gibson L. J. 2015. Comparison of the Structure and Flexural Properties of Moso, Guadua and Tre Gai Bamboo. Construction and Building Materials. 90: 11-17. DOI: https://doi.org/10.1016/j.conbuildmat.2015.04.042.

[25] Lo, T. Y., Cui, H. Z., Tang, P. W. C., and Leung, H. C. 2008. Strength Analysis of Bamboo by Microscopic Investigation of Bamboo Fibre. Construction and Building Materials. 22: 1532-1535. DOl: https://doi.org/10.1016/j.conbuildmat.2007.03.031.

[26] Ghavami, K. 1995. Ultimate Load Behaviour of BambooReinforced Lightweight Concrete Beams. Cement and Concrete Composites. 17(4): 281-288. DOl: https://doi.org/10.1016/0958-9465(95)00018-8.

[27] Khotimah, H., Wardhani, M., and Sutiyono. 2015. Analysis of Economy on Black Bamboo Cultivation (Gigantochloa atroviolacea widjaja) for Feedstocks and Environmental Sustainability. In Proceeding of International Conference of Indonesia Forestry Researchers III. 406-415.

[28] International Organization for Standardization (ISO). 1975. Wood-Sampling Methods and General Requirements for Physical and Mechanical Tests. ISO 3129. ISO: Geneva.

[29] Javadian, A., Smith, I. F. C., and Hebel, D. E. 2020. Application of Sustainable Bamboo-based Composite Reinforcement in Structural-concrete Beams: Design and Evaluation. Materials. 13(3): 696. DOI: https://doi.org/10.3390/mal3030696.

[30] Alvin, K., and Murphy, R. 1988. Variation in Fibre and Parenchyma Wall Thickness in Culms of the Bamboo Sinobambusa Tootsik. IAWA Journal. 9(4): 353-361. DOI: https://doi.org/10.1163/22941932-90001095.

[31] Ray, A. K., Das, S. K., Mondal, S., and Ramachandrarao, P. 2004. Microstructural Characterization of Bamboo. Journal of Materials Science. 39: 1055-1060. 
DOI: https://doi.org/10.1023/B:JMSC.0000012943.27090.8f.

[32] American Society for Testing and Materials. 1994. Standard Methods of Testing Small Clear Specimens of Timber. ASTM D143-94. ASTM: West Conshohocken.
[33] Plewes, W. G., and Garden, G. K. 1964. Deflections of Horizontal Structural Members. Canadian Building Digest. 54. DOI: https://doi.org/10.4224/4000086. 